\title{
MAGNETIC AND TRANSPORT PROPERTIES OF DOUBLE PEROVSKITES
}

\author{
EMIL BURZOa
}

\begin{abstract}
The magnetic and transport properties of polycrystalline $\mathrm{Sr}_{2} \mathrm{FeMoO}_{6}$ perovskites are strongly dependent on their microstructure. A cluster glass type behavior was shown at the grain boundaries. The increase of the sintering time from 4 to $8 \mathrm{hrs}$ in $\mathrm{Sr}_{2} \mathrm{FeMo}_{1-\mathrm{x}} \mathrm{W}_{\mathrm{x}} \mathrm{O}_{6}$ and $\mathrm{Ca}_{1.5} \mathrm{La}_{0.5} \mathrm{FeMo}_{1-}$ ${ }_{x} \mathrm{~W}_{\mathrm{x}} \mathrm{O}_{6}$ series improves the crystallographic order. As a result there is an increase of both the saturation magnetizations and of spin polarizations.
\end{abstract}

Keywords: perovskites, magnetic behavior, transport properties

\section{INTRODUCTION}

The $\mathrm{A}_{2} \mathrm{BB}^{\prime} \mathrm{O}_{6}\left(\mathrm{~A}=\mathrm{Sr}, \mathrm{Ca} ; \mathrm{B}=\mathrm{Fe}\right.$ and $\left.\mathrm{B}^{\prime}=\mathrm{Mo}\right)$ double perovskites are receiving attention due to their possible spin electronics applications and magnetoresistance based devices [1,2]. The technical uses are facilitated by their Curie points located above ambient temperature.

The aristotype cubic ordered double perovskites $\mathrm{A}_{2} \mathrm{FeMoO}_{6}$ can be described by cubic sharing $\mathrm{FeO}_{6}$ and $\mathrm{MoO}_{6}$ octahedra, which alternate in three directions. The A site cations occupy the cavities formed by corner sharing octahedral network. Due to small $\mathrm{Ca}^{2+}$ cation radius, the $\mathrm{FeO}_{6}$ and $\mathrm{MoO}_{6}$ octahedra are considerably tilted in anti-phase order in the basal plane and along the crystallographic c-axis, the crystal structure of $\mathrm{Ca}_{2} \mathrm{FeMoO}_{6}$ decreasing, to monoclinic, space group $\mathrm{P} 2{ }_{1} / \mathrm{h}$ [3]. The crystal structure of $\mathrm{Sr}_{2} \mathrm{FeMoO}_{6}$, due to the same reasons, is tetragonal, space group $14 / \mathrm{mmm}$ [4].

The ideal magnetic structure of $\mathrm{A}_{2} \mathrm{FeMoO}_{6}$ can be described by an antiparallel arrangement of $\mathrm{Fe}^{3+}$ and $\mathrm{Mo}^{5+}$ magnetic moments, respectively [1]. The lower magnetization than the value of $4 \mu_{\mathrm{B}} / \mathrm{f}$.u., predicted by the above magnetic structure, is a general characteristic of these perovskites. This is the result of some competitive effects: (a) the presence of antisites, where the Mo atoms are located at the Fe position and vice versa; (2) the iron ions

a Babeş-Bolyai University, Faculty of Physics, 1 Kogalniceanu str., RO-400028, Cluj-Napoca, Romania, emil.burzo@ubbcluj.ro 
having mixed valence states. In highly ordered $\mathrm{Sr}_{2} \mathrm{FeMoO}_{6}$, both $\mathrm{Fe}^{3+}-\mathrm{Mo}^{5+}$ and $\mathrm{Fe}^{2+}-\mathrm{Mo}^{6+}$ states are evidenced [5, 6]; (3) antiphase domains [7]; (4) nonuniform distribution of constituting elements inside and at the grain interface [8]; (5) oxidation at the grain boundaries; (6) decomposition of $\mathrm{Sr}_{2} \mathrm{FeMoO}_{6}$ sample with formation of $\mathrm{SrMoO}_{4}$ [9], (7) changes with time of the $\mathrm{Fe}^{2+} / \mathrm{Fe}^{3+}$ ratio [10] and (8) the $\mathrm{Mo}^{5+}$ moment smaller than $1 \mu_{\mathrm{B}}$ /ion.

The $\mathrm{A}_{2} \mathrm{FeMoO}_{6}$ double perovskites have half metallic behaviour under the assumption of a perfectly ordered crystal structure. In this case the down-spin conduction band crossing the Fermi level, $E_{F}$, is dominated by the Fe3d-Mo4d $t_{2 g}$ states, while the up-spin band, below $E_{F}$, is mostly due to the Fe3d $e_{g}$ states [1]. Commonly, deviations from perfectly ordered crystallographic and magnetic structures are present, strongly influencing the transport properties.

Previously, we analysed the magnetic and transport properties of $\mathrm{Sr}_{2} \mathrm{FeMo}_{1-\mathrm{x}} \mathrm{M}_{\mathrm{x}} \mathrm{O}_{6}$ with $\mathrm{M}=\mathrm{W}$, Ta [11, 12], $\mathrm{Ca}_{1.5} \mathrm{La}_{0.5} \mathrm{FeMo}_{1-\mathrm{x}} \mathrm{W}_{\mathrm{x}} \mathrm{O}_{6}$ [13] and $\mathrm{A}_{2} \mathrm{Fe}_{1-\mathrm{x}} \mathrm{Ni}_{x} \mathrm{MoO}_{6}$ with $\mathrm{A}=\mathrm{Ca}[14,15]$ and $\mathrm{Sr}[16]$. Some of these perovskites have Curie temperatures above the ambient one and thus possible technical uses. The physical properties were shown to be influenced both by composition and the sintering process. As an ongoing work on double perovskites, the effects of thermal treatment and sample compositions on the magnetic and transport properties of $\mathrm{Sr}$ - and Ca-based double perovskites are investigated.

\section{RESULTS AND DATA ANALYSIS}

The $\mathrm{Sr}_{2} \mathrm{FeMoO}_{6}$ perovskites were sintered at $1300^{\circ} \mathrm{C}$ under argon flow with $1.7 \%$ (sample S-3) and $0.8 \%$ (sample S-5) hydrogen, at $\mathrm{T}=1300{ }^{\circ} \mathrm{C}$. The determined AS content by XRD was $3 \%$ for sample S-3 and $5 \%$ for the perovskite S-5. The XPS studies indicate the presence of $70 \% \mathrm{Fe}^{3+}-\mathrm{Mo}^{5+}$ and $30 \% \mathrm{Fe}^{2+}-\mathrm{Mo}^{6+}$ states.

The microstructure of sample S-3 consists from grains having 0.2$0.3 \mu \mathrm{m}$ diameter and also regions in which the grain coalesced in bands, while the perovskite S-5 is constituted from grains having 2-3 $\mu \mathrm{m}$ dimensions. The iron content in sample S-3 was little smaller, while in perovskite S-5 higher than the ideal value $(25 \%)$. The molybdenum content decreased little from the center of the grain towards their boundaries. Around the grain boundaries the iron content was by $0.7 \%(\mathrm{~S}-3)$ and $1.5 \%(\mathrm{~S}-5)$ higher than that inside the grains.

The analysis of the ${ }^{57} \mathrm{Fe}$ Mössbauer spectra, for the two $\mathrm{Sr}_{2} \mathrm{FeMoO}_{6}$ perovskites showed: (1) the AS content was $3.9 \%$ in sample S-3 and $6.5 \%$ in perovskite $\mathrm{S}-5$, in rather good agreement with the values obtained from XRD method; (2) an iron-fraction of $5.8 \%$ in S-3 and $6.2 \%$ in S-5 
perovskites, respectively are located in the antiphase domain boundaries (APB). The above differences in the microstructures of the two $\mathrm{Sr}_{2} \mathrm{FeMoO}_{6}$ perovskites are reflected in their magnetic and transport properties.

The temperature dependence of magnetization for sample S-3 is given in Fig.1.The saturation magnetization at $4.2 \mathrm{~K}, \mathrm{M}_{\mathrm{s}}=3.4 \mu_{\mathrm{B}} / \mathrm{f}$.u., is by $0.6 \mu_{\mathrm{B}}$ smaller than that estimated assuming a ferrimagnetic ordering and the already determined antisite fractions and iron valence states. The molybdenum moment was assumed to be $\cong 0.4 \mu_{\mathrm{B}} /$ atom, as determined by neutron diffraction study [17]. These data suggest the presence of antiphase domains and possible cluster glass type ordering at the grain boundaries. The saturation magnetization of sample $S-5$ is by $\cong 0.1 \mu_{\mathrm{B}}$ smaller than that of $\mathrm{S}$ 3 one, correlated with a larger fraction of antisites and APB. The saturation magnetization of sample S-3 decreased by $0.15 \mu_{\mathrm{B}} / \mathrm{f}$.u. by keeping in air around 9 months.

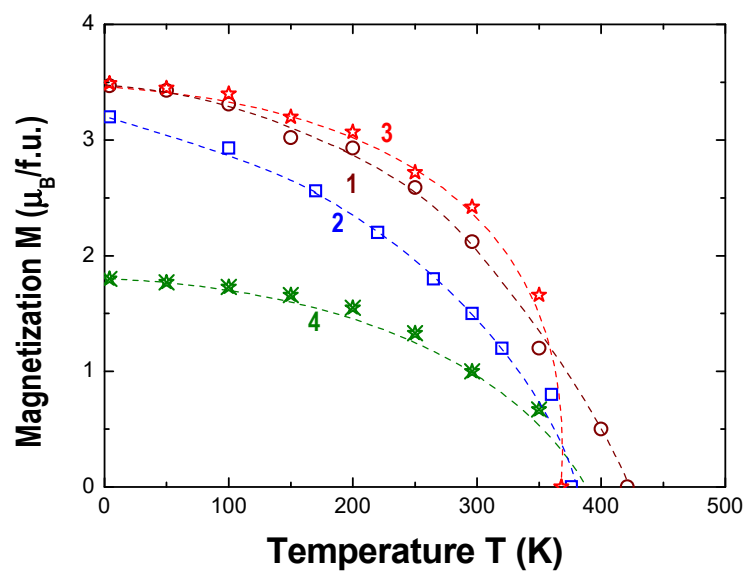

Figure 1. Thermal variations of magnetizations in $1-\mathrm{Sr}_{2} \mathrm{FeMoO}_{6}(\mathrm{~S} 3)$, 2-Sr $\mathrm{FeMo}_{0.7} \mathrm{~W}_{0.3} \mathrm{O}_{6}, 3-\mathrm{Ca}_{1.5} \mathrm{La}_{0.5} \mathrm{FeMoO}_{6}$ and $4-\mathrm{Ca}_{2} \mathrm{FeMoO}_{6}$ double perovskites

The magnetization isotherms, $M(H)$, at $T=4.2 \mathrm{~K}$, do not follow the classical approach to saturation law, suggesting the presence of an additional small magnetic contribution superposed on that due to ferrimagnetic-type ordering. The better agreement with experimental data was obtained when the $M(H)$ curves were analyzed assuming a field dependence, typical for a cluster glass system with weak anisotropy [18] - Fig.2.

$$
m(H)=M(H) / M_{s}=\left(1-a H^{-1 / 2}\right)
$$


By fitting the magnetization isotherms at $\mathrm{T}=4.2 \mathrm{~K}$, with the relation (1), values $a=0.15 \mathrm{~T}^{1 / 2}$ for sample $\mathrm{S}-3$ and $0.18 \mathrm{~T}^{1 / 2}$ for the perovskite $\mathrm{S}-5$, respectively were obtained. The above results show the presence of cluster glass type behavior at the grain boundaries, which is superposed on the main magnetic contribution resulting from the antiparallel alignment of $\mathrm{B}(\mathrm{Fe})$ and $\mathrm{B}^{\prime}(\mathrm{Mo})$ magnetizations.

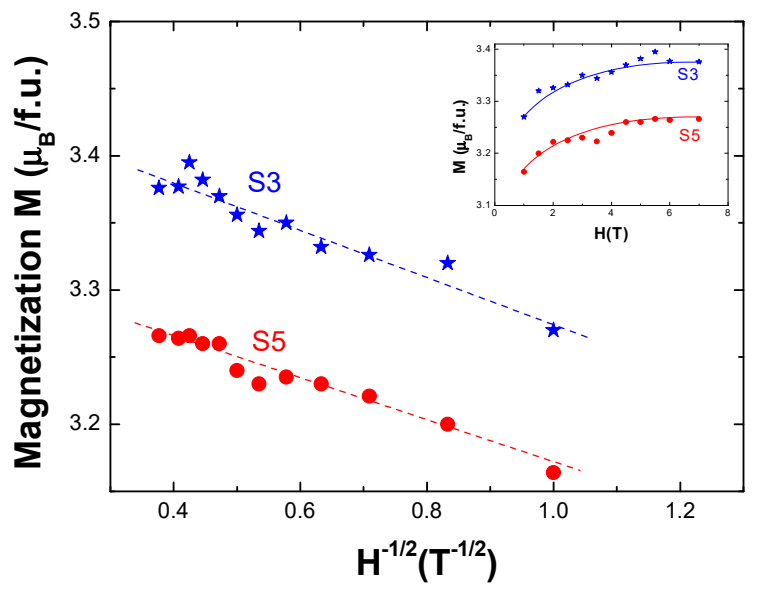

Figure 2. The magnetization isotherms, at $\mathrm{T}=4.2 \mathrm{~K}$, for two $\mathrm{Sr}_{2} \mathrm{FeMoO}_{6}$ perovskites

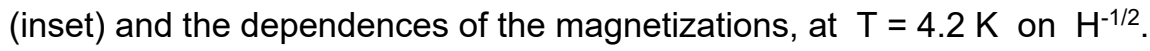

The fitted curves are shown by dashed lines.

The previous studies on $\mathrm{Sr}_{2} \mathrm{FeMoO}_{6}$ perovskites showed both semiconducting and metallic behavior, depending on the preparation method $[19,20]$. Differences between resistivities of the two $\mathrm{Sr}_{2} \mathrm{FeMoO}_{6}$ samples correlated with their microstructures, are also present, as seen in Fig.3. The perovskite S-3 has a resistivity by two orders of magnitude lower than that of the S-5 sample. The higher resistivity of sample S-5 can be attributed mainly to differences in the compositions inside the grains and at their interfaces. The iron content at the grain boundary is by $\cong 1.5 \%$ higher, and consequently the cluster glass contribution to the magnetizations, as suggested from the analysis of magnetizations isotherms. The number of antisites in sample S-5 is twice than that in perovskite S-3. The lower hydrogen content in the mixture with argon, used during sintering, can lead to possible oxidation of the grain boundaries, affecting also the transport properties of sample S-5. 


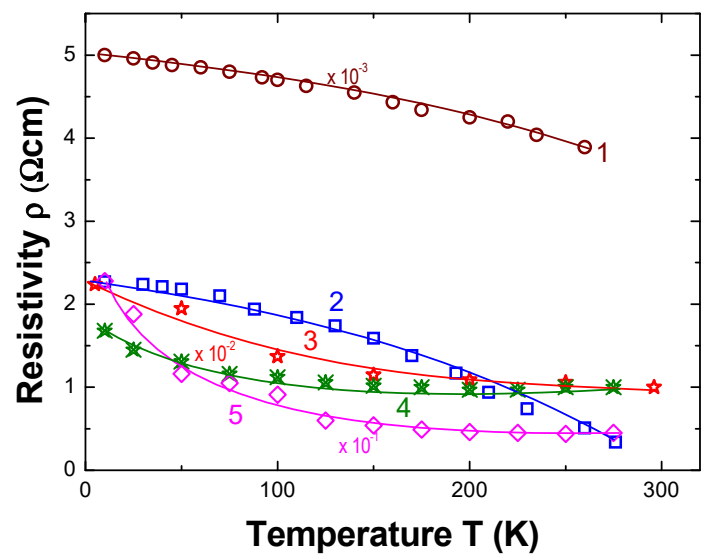

Figure 3. The temperature dependences of the resitivities for $1-\mathrm{Sr}_{2} \mathrm{FeMoO}_{6}(\mathrm{~S}-3)$,

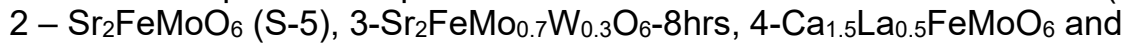
5-Ca1.5La0.5FeMo $0.7 \mathrm{~W}_{0.3} \mathrm{O}_{6}$

The magnetoresistances (MR) of the perovskites are determined by two contributions: (1) the spin disorder inside the grains, proportional to the external field, $M_{\mathrm{d}}=-\mathrm{bH}$; (2) the intergrain magnetic tunneling magnetoresistance (ITMR) which depends of the structure and magnetic state at the grain boundaries. The contribution of magnetic state at the grain boundaries to the ITMR, MR $\mathrm{i}_{\mathrm{i}}$ in polycrystalline perovskites, can be analysed for systems where the applied field is smaller than the exchange field [21, 22]. By using the mean field approximation, the exchange interactions parameters inside and between the $\mathrm{B}$ and $\mathrm{B}^{\prime}$ magnetic sublattices in $\mathrm{Sr}_{2} \mathrm{FeMoO}_{6}$, were determined $\left(J_{B B^{\prime}}=-17, J_{B B}=98\right)$ and on this basis, the exchange field. The exchange field acting on $B$ sublattice, of $200 \mathrm{~T}$, is by $\cong 30$ times higher than the field used in present measurements. Consequently, the model [21, 22] can be used also in analysing the transport properties of $\mathrm{A}_{2} \mathrm{FeMoO}_{6}$-based series.

Starting from a network of tunnel junctions, whose electrodes are double perovskite grains, separated by an insulating layer and assuming elastic tunneling across a single barrier, averaged over random grain orientations, the $\mathrm{MR}_{\mathrm{i}}$ contribution to magnetoresistance can be described by [22]:

$$
M R_{i}=\Delta \rho(\Delta H, T) / \rho(H, T)=-P^{2} m(H)^{2}\left[1+P^{2} m(H)^{2}\right]^{-1}
$$

By $P$ is denoted the spin polarization and $m(H)$ is the reduced magnetization at the grain boundaries, given by the relation (1). As seen from Fig. 4, the low field magnetoresistance of polycrystalline perovskites is determined by spin polarized tunneling between the grains and the high field contribution is related mainly to the intragrain contribution. 


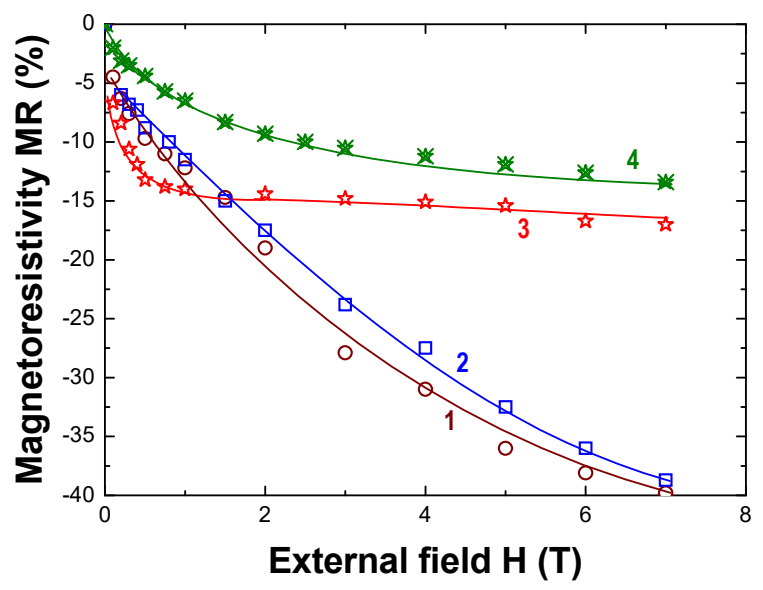

Figure 4. The field dependences of the magnetoresistances, at $\mathrm{T}=10 \mathrm{~K}$ for 1- $\mathrm{Sr}_{2} \mathrm{FeMoO}_{6}(\mathrm{~S}-3), 2-\mathrm{Sr}_{2} \mathrm{FeMo}_{0.7} \mathrm{~W}_{0.3} \mathrm{O}_{6}, 3-\mathrm{Ca}_{2} \mathrm{FeMoO}_{6}$ and 4-Ca1.5La0.5 $\mathrm{FeMoO}_{6}$

By fitting the experimentally determined magnetoresitances with the relation $M R=M R_{d}+M R_{i}$, the temperature dependences of the spin polarizations, $\mathrm{P}$, were determined in both $\mathrm{Sr}_{2} \mathrm{FeMoO}_{6}$ samples as well as in others pseudoquaternary perovskites - Fig. 5. The spin polarization of sample S-3 is of $58 \%$, at $\mathrm{T}=10 \mathrm{~K}$, and decreases nearly linearly with temperature. The extrapolated temperatures where $\mathrm{P}=0$, are close to the Curie points. The spin polarization of perovskite $\mathrm{S}-5$, at $\mathrm{T}=10 \mathrm{~K}$ is nearly half as compared with that evidenced in sample $\mathrm{S}-3$.

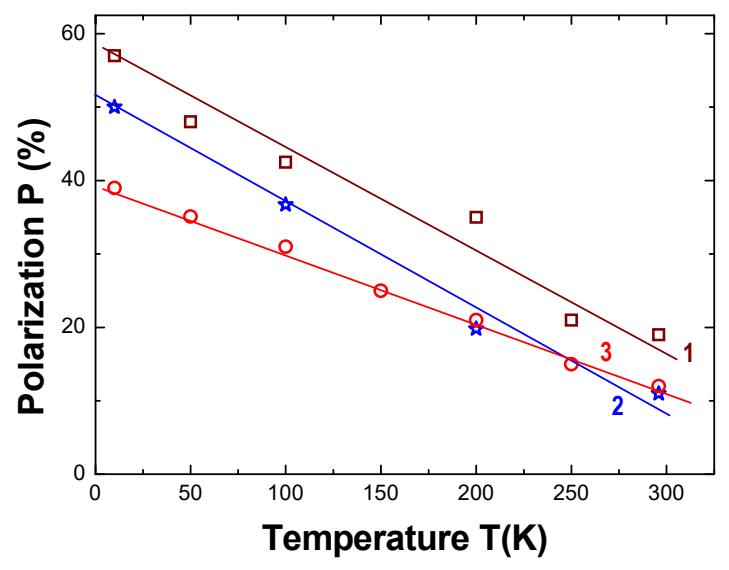

Figure 5. Thermal variations of spin polarizations in $1-\mathrm{Sr}_{2} \mathrm{FeMoO}_{6}(\mathrm{~S}-3)$, $2-\mathrm{Sr}_{2} \mathrm{FeMo}_{0.7} \mathrm{~W}_{0.3} \mathrm{O}_{6}, 3-\mathrm{Ca}_{2} \mathrm{FeMoO}_{6}$ perovskites. 
The comparative analysis of the physical properties of $\mathrm{Sr}_{2} \mathrm{FeMoO}_{6}$ perovskites sintered in different conditions show: (1) the microstructure of the perovskites, the homogeneity of the grain and at the grain boundary are significantly influenced by the sintering conditions; (2) the magnetic properties are mainly determined by the iron valence states and the antisite content; (3) the transport properties are influenced by the energy of the barriers at the grain boundaries, respectively.

The effect of substitutions of Mo by $\mathrm{W}$ [11, 23-25], of Fe by $\mathrm{Ni}$ and of $\mathrm{Ca}_{2}$ by $\mathrm{Ca}_{1.5} \mathrm{La}_{0.5}$ [13-16] on the physical properties of double perovskites were also analysed. The composition dependences of the Curie temperatures for $\mathrm{A}_{2} \mathrm{Fe}_{1-\mathrm{x}} \mathrm{Ni}_{\mathrm{x}} \mathrm{MoO}_{6}$ with $\mathrm{A}=\mathrm{Sr}$ and $\mathrm{Ca}, \mathrm{Sr}_{2} \mathrm{FeMo}_{1-\mathrm{x}} \mathrm{W}_{\mathrm{x}} \mathrm{O}_{6}$ and $\mathrm{Ca}_{1.5} \mathrm{La}_{0.5} \mathrm{FeMo}_{1-\mathrm{x}} \mathrm{W}_{\mathrm{x}} \mathrm{O}_{6}$ double perovskites are shown in Fig. 6. Although the Curie points of $\mathrm{Sr}_{2} \mathrm{FeMo}_{1-\mathrm{x}} \mathrm{W}_{\mathrm{x}} \mathrm{O}_{6}$ decrease, as molybdenum is replaced by tungsten, these remain located above the room temperature. The presence of $W$ improve the crystallographic ordering. The increase of sintering time at $1300^{\circ} \mathrm{C}$, from 4 to $8 \mathrm{hrs}$, leads to a better homogeneity of the grains and diminishes the number of antisites [11]. The cluster glass contribution to the magnetization also decreases. The presence of tungsten, influence only little the magnetoresistance. Even if $30 \%$ of Mo is replaced by W, only a small reduction of spin polarization, as compared to that of the end series member can be shown - Figs. 4 and 5 .

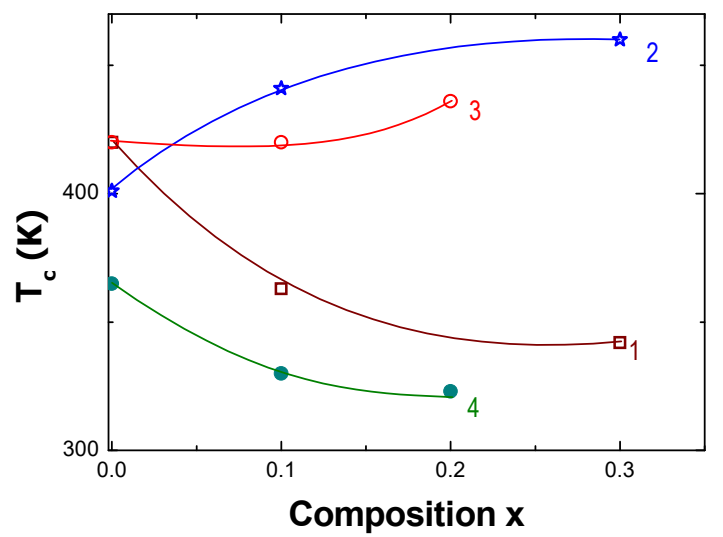

Figure 6. The composition dependences of the Curie temperatures in 1-Sr $\mathrm{FeMo}_{1-\mathrm{x}} \mathrm{W}_{\mathrm{x}} \mathrm{O}_{6}, 2-\mathrm{Ca}_{1.5} \mathrm{La}_{0.5} \mathrm{FeMo}_{1-\mathrm{x}} \mathrm{W}_{\mathrm{x}} \mathrm{O}_{6}, 3-\mathrm{Sr}_{2} \mathrm{Fe}_{1-\mathrm{x}} \mathrm{Ni}_{\mathrm{x}} \mathrm{MoO}_{6}$ and $4-\mathrm{Ca}_{2} \mathrm{Fe}_{1-\mathrm{x}} \mathrm{Ni}_{x} \mathrm{MoO}$ double perovskites.

The partial substitutions of $\mathrm{Mo}$ by $\mathrm{W}$ in $\mathrm{Ca}_{1.5} \mathrm{La}_{0.5} \mathrm{FeMo}_{1-\mathrm{x}} \mathrm{W}_{\mathrm{x}} \mathrm{O}_{6}$ series, increase also the crystallographic ordering. As a result, higher Curie temperatures and saturation magnetizations, as compared to end series 
perovskite, are shown [13]. There are little changes in the magnetoresistances of the $\mathrm{W}$ substituted samples. The spin polarization at $\mathrm{T}=10 \mathrm{~K}$, increase from $40 \%$ for $\mathrm{x}=0$ up to $53 \%$ when $30 \%$ Mo is replaced by W.

The iron valence states in $\mathrm{Ca}_{1.5} \mathrm{La}_{0.5} \mathrm{FeMoO}_{6}$ are dependent on pressure. As the pressure increases, the resistivities decrease followed by an abrupt drop at $p \cong 2 \mathrm{GPa}$ [26-28], correlated with changes in iron valence states [26]. This suggests that the transport properties of the perovskites can be tuned by pressure.

The Curie temperatures of $\mathrm{A}_{2} \mathrm{Fe}_{1-x} \mathrm{Ni}_{x} \mathrm{MoO}_{6}$ double perovskites increase as iron is substituted by nickel when $A=S r$ and decrease if $A=C a$. The above trend can be analysed in correlation with exchange interactions between B and B' sites magnetizations, resulting from the composition dependence of the antisite content [16].

We note that in $\mathrm{La}_{1-\mathrm{x}} \mathrm{Pb}_{\mathrm{x}} \mathrm{MnO}_{3}$ perovskite, a spin polarization of $\cong 90$ $\%$ was obtained for a composition $x=0.4[29,30]$. Unfortunately, the Curie temperatures of the series are rather low and consequently cannot be used in spintronic applications, working at room temperature.

\section{CONCLUSIONS}

The physical properties of $\mathrm{A}_{2} \mathrm{FeMoO}_{6}$ double perovskites with $\mathrm{A}=\mathrm{Sr}$, $\mathrm{Ca}$, as well as of series obtained by substitutions at $\mathrm{A}, \mathrm{Fe}$ and Mo sites are strongly dependent on the sintering process (temperature, time, atmosphere). The partial substitution of Mo by $\mathrm{W}$ improve the crystallographic ordering. Their magnetic and transport properties are influenced by aging or by keeping in air.

\section{EXPERIMENTAL SECTION}

The double perovskites were prepared by solid state reaction. The amounts of $\mathrm{SrCO}_{3}, \mathrm{CaCO}_{3}, \mathrm{Fe}_{2} \mathrm{O}_{3}, \mathrm{La}_{2} \mathrm{O}_{3}, \mathrm{WO}_{3}$ and $\mathrm{NiO}$ powders, corresponding to the requested sample compositions, were mixed and calcinated in argon atmosphere at $\mathrm{T}=900{ }^{\circ} \mathrm{C}$. The calcinated powders were pelletized and sintered at temperatures $1200-1300{ }^{\circ} \mathrm{C}$, between 4 and $8 \mathrm{hrs}$, in a stream of argon flow atmosphere having $0.8 \%$ up to $1.7 \%$ hydrogen.

The XRD spectra showed the presence of only one phase. The spectra were analysed by Rietveld method by using a TOPAS program [31]. In this way, the lattice parameters and antisite (AS) content were determined. The $\mathrm{Sr}_{2} \mathrm{FeMo}_{1-\mathrm{x}} \mathrm{W}_{\mathrm{x}} \mathrm{O}_{6}$ and $\mathrm{Ca}_{1.5} \mathrm{La}_{0.5} \mathrm{FeMo}_{1-\mathrm{x}} \mathrm{W}_{\mathrm{x}} \mathrm{O}_{6}$ series with $\mathrm{x} \leq 0.3$, crystallize in 
a tetragonal and monoclinic structure types, respectively. The $\mathrm{A}_{2} \mathrm{Fe}_{1-\mathrm{x}} \mathrm{Ni}_{\mathrm{x}} \mathrm{MoO}_{6}$ with $\mathrm{A}=\mathrm{Sr}$, Ca perovskites form solid solutions up to $\mathrm{x}=0.2$.

Scanning electron microscopy (SEM) and energy disperse spectroscopy (EDS) measurements were made with a JEOL-type equipment. The compositions, grain dimensions and the distribution of constituting elements along the grains were analysed.

Magnetic measurements have been performed by extraction method, in the temperature range $4.2 \mathrm{~K}$ to Curie points, in fields up to $7 \mathrm{~T}$. The ${ }^{57} \mathrm{Fe}$ Mössbauer studies have been made, at $\mathrm{T}=77 \mathrm{~K}$, on $\mathrm{Sr}_{2} \mathrm{FeMoO}_{6}$ perovskites synthesized in different conditions.

The resistivity and magnetoresistance were investigated in the $10 \mathrm{~K} \leq$ $\mathrm{T} \leq 300 \mathrm{~K}$ temperature range and fields up to $7 \mathrm{~T}$, by using the four terminal method.

\section{ACKNOWLEDGMENTS}

We would like to acknowledge support from the Romanian UEFISCDI project number PN-III-P4-ID-PCCF-2016-0112 Nr. 6.

\section{REFERENCES}

1. K. I. Kobayashi; T. Kimura; H. Sawada; K. Terakura; Y. Tokura; Nature, 1998, 395,677

2. D. Rubi; I. Nogues; J. S. Munoz; J. Fountcuberta; Mat. Sci. Eng. 2006, B126, 279

3. R. P. Borges; R. M. Thomas; C. Cullinan; J. M. D. Coey; B. Suryanarayanan, L. Ben-Dor; I. Pinsard-Gaudart; A. Recolevschi; J. Phys.: Condens. Matter, 1999, 11,1445

4. E. Burzo; Perovskites, Landolt-Börnstein Handbook, Springer Verlag, 1996, vol. 27F1ß

5. K. Kuepper et all; Phys. Stat. Solidi (a), 2004, 201, 3252

6. M. Raekers et all; J. Opt. Adv. Mater, 2006, 8, 455

7. J. M. Greneche; M. Venkatesan; R. Suryanarayanan; J. M. D. Coey; Phys. Rev. 2001, B63, 174403

8. D. Yang; T. Yang; Q. Sun; Y. Chen; G. L. Lapronti; J. Alloys. Comp. 728, 337 (2017)

9. J. Navarro; C. Frontera; D. Rubi; N. Mestres; J. Frontcuberta; Mater. Res. Bull., 2003, 38, 1477

10. K. Kuepper; M. Raekers; C. Taubitz; H. Hesse; M. Neumann; A. T. Young, C. Piamonteze; F. Bondino; K. C. Prince; J. Appl. Phys., 2008, 104, 036103

11. E. Burzo; I. Balasz; M. Valeanu; I. G. Pop; J. Alloys Comp., 2011, 509, 105

12. E. Burzo; I. Balasz; S. Constantnescu; I. G. Deac; J. Magn. Magn. Mater., 2007, 316, e741 
13. E. Burzo; I. Balasz; M. Valeanu; D. P. Kozlenko; A. V. Rutkauscas; B. N. Savenko; J. Alloys Comp., 2015, 621, 71

14. E. Burzo; I. Balasz, Rom.J. Phys., 2017, 62, 601;

15. E. Burzo; I. Balasz; AIP Conf. Proc., 2016, 1722, 080003

16. E. Burzo; G. Souca; J. Mater. Sci.: Mater. Electron. 2021, 32, 2200

17. D. Sanchez; J. A. Alonso; M. Garcia-Hernandez; M. J. Martinez-Lope; J. L. Martinez; A. Mellergard; Phys. Rev., 2000, B65, 104426

18. J. Tejada; B. Martinez; A. Labarta; E. M. Chudnovsky; Phys. Rev. , 1991, B44, 7698

19. Y. Tomioka; T. Okuda; Y. Okamoto; R. Kumai; K. I. Kobayashi; Y. Tokura; Phys. Rev. , 2000, B61, 422

20. G. Suchaneck; N. Kalanda; E. Artiukh; M. Yarmolich; N. A. Sobolev; J. Alloys Comp. 2021, 860, 158526

21. D. Niebieskikwiat; F. Prado; A. Caniero; R. D. Sanchez; Phys. Rev., 2004, B70, 132412

22. D. Serrate; J. M. De Teresa; R. A. Algarabel; M. R. Ibarra; J. Galibert; Phys. Rev., 2005, B71, 104409

23. S. Ray; A. Kumar; S. Magundar; E. V. Sampathkumaran; D. D. Sarosa; J. Phys. : Condens Matter, 13607 (2001)

24. K. I. Kobayashi; T. Okuda; Y. Tomioka; T. Kimura; Y. Tokura; J. Magn. Magn. Mater., 2000, 218, 17

25. M. Karppinen; H. Yamauchi; Y. Yasukawa; J. Linden; F. S. Chan; R. S. Liu; J. M. Chen; Chem Mater., 2003, 15, 4118

26. E. Burzo; D. P. Kozlenko; N. T. Dang; S. E. Kichanov; N. O. Golosova; J. Alloys Comp., 2016, 664, 363

27. P. Zhao; R. C. Yu; F. Y. Li; Z.H. Liu; M. Z. Jin; C. Q. Jin; J. Appl. Phys., 2002, 92, 1942

28. D. Morrocchelli; P. Postorino; D. D. Castro; E. Arcangeletti; P. Dore; M. C. Guidi; S. Ray; D. D. Sarma; Phys. Rev., 2007, B76, 172405

29. E. Burzo; I. Balasz; M. Isobe; Y. Ueda, J. Alloys Comp., 2012, 535, 129

30. E. Burzo; I. Balasz; I. G. Deac; M. Neumann; Physica, 2008, B403, 1601

31. DIFRAC plus TOPAS General profile and structure analysis software for powder diffraction data, 2001, Bruker AXS Gmb, Karlsruhe 